\title{
K-Band Low Phase Noise VCO Based on Q-Boosted Switched Inductor
}

\author{
Zhe Chen ${ }^{1} * \mathbb{C}^{\mathbb{O}}$, Ji-Xin Chen ${ }^{1}$, Pinpin Yan ${ }^{1}$, Debin Hou ${ }^{1}$ and Fang Zhu ${ }^{2}$ \\ 1 State Key Lab of Millimeter Waves, School of Information Science and Engineering, Southeast University, \\ Nanjing 210096, China; jxchen@seu.edu.cn (J.-X.C.); yanpinpin@seu.edu.cn (P.Y.); dbhou@seu.edu.cn (D.H.) \\ 2 Key Laboratory of RF Circuits and Systems of Ministry of Education, School of Electronics and Information, \\ Hangzhou Dianzi University, Hangzhou 310018, China; fangzhu@hdu.edu.cn \\ * Correspondence: zhechen@seu.edu.cn; Tel.: +86-150-6225-9338
}

Received: 13 September 2019; Accepted: 5 October 2019; Published: 8 October 2019

check for updates

\begin{abstract}
In this article, the development of the K-band low phase noise voltage-controlled oscillator (VCO) based on Q-boosted switched inductor is presented. Compared with the conventional switched inductor, the eddy current will be decreased using a 2-turn secondary coil, and then the dissipated power from the switch on-resistance will also be decreased, leading to a boosted inductor $Q$ at switch ON-state. The equivalent inductance, quality factor, and self-resonance frequency at switch ON/OFF states are analyzed and derived. For comparison, K-band VCOs have been designed and fabricated in a 130nm BiCMOS process with the Q-boosted and conventional switched inductors. Measured results show that the phase noise has been typically improved by $2-5 \mathrm{~dB}$ at $100 \mathrm{kHz}$ and $1 \mathrm{MHz}$ offset at switch ON-state, using the Q-boosted switched inductor.
\end{abstract}

Keywords: K-band; quality factor; phase noise; switched inductor; voltage-controlled oscillator

\section{Introduction}

Nowadays, with the increasing demand for multi-standard, high data-rate wireless communications, voltage-controlled oscillators (VCOs) that are able to cover multiple frequency bands attract more and more attention. The capacitive tuned LC VCOs are preferred for their low phase noise and low power dissipation. An ultra-wideband VCO with a tuning range of $70 \%$ and a center frequency of $1.8 \mathrm{GHz}$ has been reported [1]. For higher operation frequency or millimeter waveband, because the quality factor $(\mathrm{Q})$ of the capacitor degrades rapidly with frequency, the tuning range is often kept relatively narrow for higher tank $Q$. To further increase the tuning range without sacrificing the tank $Q$, magnetic tuning has also been proposed, such as switched extra inductors that are coupled to the main inductors [2-4], directly controlling the loop length of the main inductor in the LC tank [5], switched guard-ring [6], and switched substrate-shield [7], that are artificial grounded metal shield to the inductor. In this way, better performance can be achieved for the tuning range, phase noise and power consumption. However, compared to conventional LC VCOs, the quality factor of the switchable inductor will significantly degenerate when the switch is at the ON-state due to the parasitic on-resistance [8], resulting in poor phase noise and higher power consumption. Therefore, the magnetic tuning approach is not superior to conventional VCOs with discrete oscillating cores except for less area, unless the $Q$ of the switchable inductor can be improved, especially at switch ON-state. Although a Q-boosted switched inductor has been implemented [9], the work is related to PCB inductors with SMD PIN diode as RF switch for low-GHz applications. There are few works related to Q-boosting for on-chip switched inductors at ON-state or VCOs using Q-boosted switched inductor to improve phase noise at tens-GHz or millimeter-wave band. 
In this article, the design of K-band low phase noise VCO based on Q-boosted switched inductor using NMOS transistor as the switch is presented. A quality factor boosting approach for the K-band on-chip switched inductor is proposed. The major design issues, such as the equivalent inductance, quality factor, and self-resonance frequency of the inductor at the switch ON/OFF states are analyzed and derived, based on the equivalent circuit. 1:n transformers with arbitrary parameter $n$ are analyzed in the analytical expressions and design trade-offs are discussed, such as self-resonance frequency and $Q$ limitation at the switch ON/OFF states. To avoid self-resonance frequency degeneration, a 1:2 transformer and an optimized switch size are utilized for the Q-boosted switched inductor. For comparison, both the proposed Q-boosted and the conventional switched inductors have been used for K-band VCOs design and fabrication in the $130 \mathrm{~nm}$ BiCMOS process. Measured results have shown an improved VCO phase noise at $100 \mathrm{kHz}$ and $1 \mathrm{MHz}$ offset by 2-5 dB at switch ON-state, with the proposed Q-boosted switched inductor.

\section{Design and Implementation of the Low Phase Noise VCO with Q-boosted Switched Inductor}

Figure 1 shows the schematic of the Colpitts VCO and equivalent circuits of the switched inductor at the switch ON and OFF states. The switched inductor consists of 1:n inductor-loaded transformer and NMOS transistor as the RF switch, which is connected to the secondary coil and controlled by Vsw. $L_{P}$ and $L_{S}$ are the self-inductances of the primary and secondary coil, $\mathrm{k}$ is the coupling coefficient, and $\mathrm{n}$ is the turn ratio. $\mathrm{R}_{\text {Soff }}, \mathrm{C}_{\text {Soff }}, \mathrm{Y}_{\text {Pon }}$ and $\mathrm{C}_{\text {Pon }}$ are the equivalent circuit parameters for the NMOS switch at the $\mathrm{OFF} / \mathrm{ON}$ state. For simplification, the resistances and capacitances between the primary coil and secondary coil are omitted. Intuitively, for ideal conductive coil, the magnetically induced (eddy) current in the secondary coil is such that its resulting magnetic field will cancel the magnetic flux opposed by the excitation magnetic field of the primary coil. In order to cancel the same magnetic flux, the eddy current in the n-turn secondary coil will decrease to $1 / n$. Thus, the energy loss due to the switch on-resistance can be decreased to $1 / \mathrm{n}^{2}$, leading to a boosted inductor $\mathrm{Q}$.

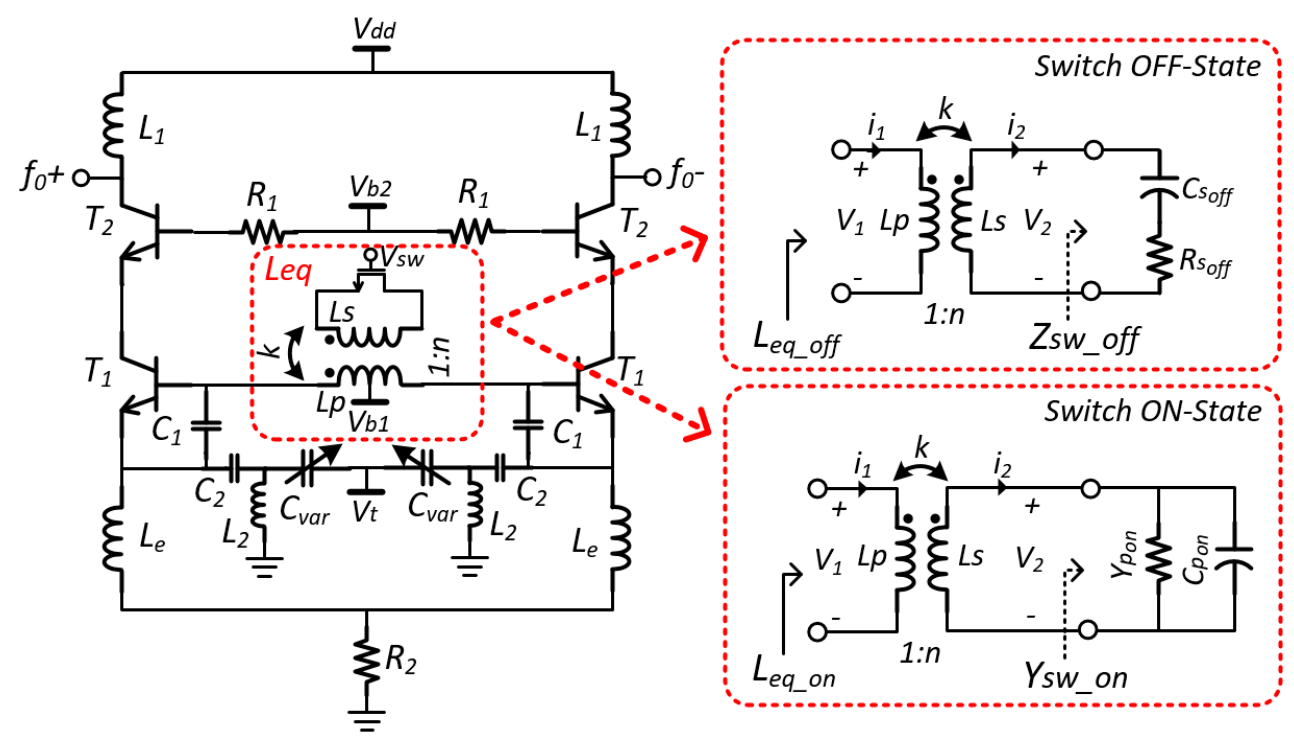

Figure 1. Schematic of the differential Colpitts VCO (voltage-controlled oscillators), and equivalent circuits of switched inductor at the switch $\mathrm{ON} / \mathrm{OFF}$ state.

In order to simplify the switch model, the ON-admittance $Y_{S W_{-} O N}=Y_{P o n}+j \omega C_{P o n}$ and OFF-impedance $Z_{\text {SW_OFF }}=R_{\text {Soff }}+1 /\left(j \omega C_{\text {Soff }}\right)$ are simulated for the NMOS transistor with width of $6 \mu \mathrm{m}, 10 \mu \mathrm{m}, 14 \mu \mathrm{m}$, and channel length of $0.12 \mu \mathrm{m}$. The simulated results are shown in Figure 2. 


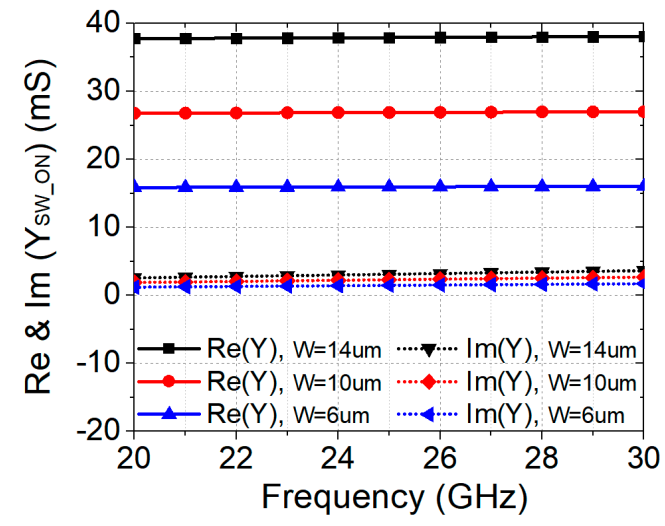

(a)

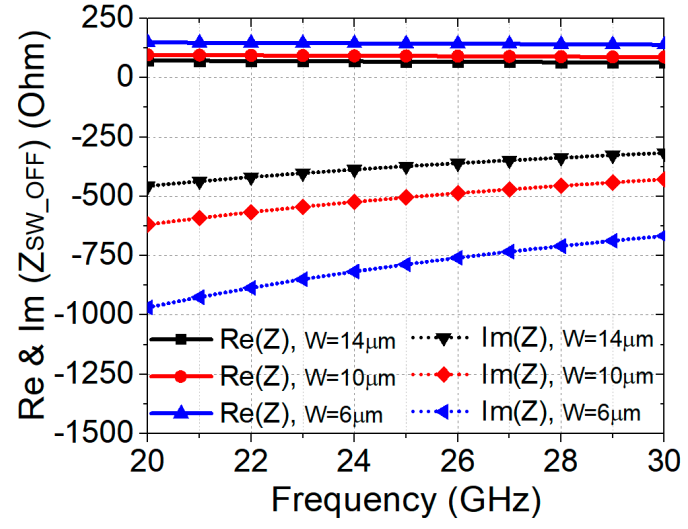

(b)

Figure 2. Simulated results for NMOS transistor as RF switch with width of $6 \mu \mathrm{m}, 10 \mu \mathrm{m}$, and $14 \mu \mathrm{m}$ in $\mathrm{K}$-band (a) admittance $\mathrm{Y}_{\mathrm{SW}} \mathrm{ON}$ when $\mathrm{Vsw}=1.2 \mathrm{~V}$; (b) impedance $\mathrm{Z}_{\mathrm{SW}} \mathrm{OFF}$, when Vsw $=0 \mathrm{~V}$.

It is noted that, $\left|Y_{\text {Pon }}\right|>10\left|j \omega C_{\text {Pon }}\right|$ and $\left|1 /\left(j \omega C_{\text {Soff }}\right)\right|>5\left|R_{\text {Soff }}\right|$, so $C_{\text {Pon }}$ and $R_{\text {Soff }}$ can be omitted for first-order simplification. The same simplified switch model can be found in [2]. The excitation is applied to the primary coil $\left(L_{p}\right)$, with voltage $v_{1}$ and current $i_{1}$,

The equivalent inductance $\mathrm{L}_{\mathrm{eq}}$ and current in the secondary coil $\mathrm{i}_{2}$ can be calculated with the following equations,

$$
\begin{gathered}
\mathrm{v}_{1}=\mathrm{sL}_{\mathrm{p}} \mathrm{i}_{1}-\mathrm{sMi}_{2} \\
\mathrm{v}_{2}=\mathrm{sMi}_{1}-\mathrm{sL}_{\mathrm{s}} \mathrm{i}_{2} \\
\mathrm{n}=\sqrt{\mathrm{L}_{\mathrm{s}} / \mathrm{L}_{\mathrm{p}}} \\
\mathrm{M}=\mathrm{k} \sqrt{\mathrm{L}_{\mathrm{s}} \cdot \mathrm{L}_{\mathrm{p}}}
\end{gathered}
$$

where $\mathrm{k}$ is the coupling coefficient and $\mathrm{M}$ is the mutual inductance between the primary and secondary coils. Then, at switch ON-state, the equivalent inductance $\mathrm{L}_{\text {eq_on }}$ and quality factor $\mathrm{Q}_{\text {Ind_on }}$ can be derived as.

$$
\begin{gathered}
\mathrm{L}_{\text {eq_on }} \approx \mathrm{L}_{\mathrm{p}} \cdot\left(1-\frac{\mathrm{k}^{2} \mathrm{~L}_{\mathrm{S}}^{2}}{\mathrm{~L}_{\mathrm{S}}^{2}+\frac{1}{\omega^{2} \mathrm{Y}_{\text {Pon }}^{2}}}\right) \\
\mathrm{Q}_{\text {Ind_on }} \approx \frac{\mathrm{n}^{2} \omega\left(1-\mathrm{k}^{2}\right) \mathrm{L}_{\mathrm{p}} \mathrm{Y}_{\text {Pon }}}{\mathrm{k}^{2}}+\frac{1}{\mathrm{n}^{2} \omega \mathrm{k}^{2} \mathrm{~L}_{\mathrm{p}} \mathrm{Y}_{\text {Pon }}}
\end{gathered}
$$

At switch OFF-state, the self-resonance frequency $\omega_{\text {Res_off }}$ can be expressed as

$$
\omega_{\text {Res_off }}^{2} \approx \frac{1}{n^{2} L_{P}\left(1-k^{2}\right) C_{\text {Soff }}}
$$

From (6), if $n^{2} \omega\left(1-k^{2}\right) L_{p} Y_{p o n} / k^{2}>>1 /\left(n^{2} \omega k^{2} L_{p} Y_{p o n}\right)$, the former term will be the main contributor to $\mathrm{Q}_{\text {Ind_on }}$, which will linearly increase as $\mathrm{n}^{2}$ increases. To achieve this,

$$
\mathrm{n}^{2} \omega \sqrt{1-\mathrm{k}^{2}} \mathrm{~L}_{\mathrm{p}} \mathrm{Y}_{\text {Pon }}>>1
$$

is equally required. For typical $\omega$ of $\sim 2 \pi \cdot 25 \mathrm{GHz}, \mathrm{L}_{\mathrm{p}}$ of $\sim 500 \mathrm{pH}$, and $\mathrm{k}$ of $\sim 0.5, \mathrm{n}^{2} \mathrm{Y}_{\text {Pon }}$ should be much larger than $14.7 \mathrm{mS}$, which means the inductor $\mathrm{Q}$ will increase at the $\mathrm{ON}$-state if using the larger size for the switch transistor, or more turns for the secondary coil. However, this will also lead to 
large parasitic capacitance at the switch OFF-state, and degeneration of inductor operation frequency because the self-resonance frequency will decrease with $1 / \mathrm{n}^{2}$, as derived in (7). To demonstrate the Q-boosting effect at K-band, $\mathrm{W}=10 \mu \mathrm{m}$ and $\mathrm{n}=2$ are chosen in the following design. Figure $3 \mathrm{a}, \mathrm{b}$ shows the normal switched inductor with a secondary turn of $n=1$ and the proposed Q-boosted switched inductor with $\mathrm{n}=2$. Top metal layer with a thickness of $4 \mu \mathrm{m}$ and height to the ground of $9.62 \mu \mathrm{m}$ has been used for the inductor for high $\mathrm{Q}$ application. The design is co-simulated with Agilent Advanced Design System (ADS) and Ansoft High Frequency Structure Simulator (HFSS).

Figure $3 c$ shows the simulated inductance $\mathrm{L}_{\mathrm{eq}}$. At $25 \mathrm{GHz}$, the $\mathrm{L}_{\mathrm{eq}}$ can be reconfigured as $0.42 \mathrm{nH} / 0.49 \mathrm{nH}$ (ON/OFF-state) for the normal switched inductor (dashed line), and $0.416 \mathrm{nH} / 0.496 \mathrm{nH}$ (ON/OFF-state) for the proposed Q-boosted switched inductor (solid line). Figure 3d shows the simulated quality factor $Q$. At the $\mathrm{ON}$-state, the Q-boosted switched inductor has $Q$ of 12.3-14.8 for 20-30 GHz, while the normal switched inductor has $Q$ of 7.8-8. This shows that the quality factor can be improved with the proposed Q-boosting technique. It is noted because the derivation of (1)-(4) does not take into account the resistance of the secondary coil and other ohm-loss in the inductor, the Q-boosting factor is much less than $\mathrm{n}^{2}$. At the OFF-state, this technique will degenerate the $\mathrm{Q}$ from 23.8 to $16.6-21.9$, which results from larger parasitic capacitance and resistance of the secondary coil at OFF-state. But this degeneration is acceptable, because the overall $Q$ of the switched inductor is mostly limited by the ON-state performance. To further validate the proposed Q-boosted approach, $1 \mathrm{~V}$ peak-peak differential AC-voltage-source has been used as input at the primary inductor, and the Eddy currents on the NMOS transistor and secondary inductor are simulated at the switch ON-state. Figure 3e shows the transient Eddy currents at $25 \mathrm{GHz}$ with the normal switched inductor (dashed line) and the proposed Q-boosted switched inductor (solid line). The amplitude of the sinusoid Eddy current for $\mathrm{n}=2$ (proposed) is $3.8 \mathrm{~mA}$, while the Eddy current for $\mathrm{n}=1$ (conv) is $6.0 \mathrm{~mA}$. Figure $3 \mathrm{f}$ shows the magnitude of the Eddy currents from $20-30 \mathrm{GHz}$, which is $1.5-1.6$ times higher on conventional inductor than that on the proposed inductor. With the same NMOS transistor RF switch, smaller eddy current means smaller ohm-loss for the same ON-resistance, thus boosted inductor Q. Then, K-band Colpitts VCOs are designed with the Q-boosted switched inductor and normal switched inductor, for comparison. As shown in Figure 1, the LC tank consists of $C_{1}, C_{2}, L_{2}, C_{v a r}, L_{e}$, and the switched inductor $\mathrm{L}_{\mathrm{eq}} \cdot \mathrm{C}_{\mathrm{var}}$ is the capacitance of the varactor, which is biased with tuning voltage, $\mathrm{V}_{\mathrm{t}}$. Bipolar transistor $T_{1}$ generates the desired negative resistance to sustain oscillation. The biasing condition for $T_{1}$ and $T_{2}$ are optimized for noise and output power. The emitter lengths for $T_{1}$ and $T_{2}$ are $18 \mu \mathrm{m}$ and $10 \mu \mathrm{m}$, respectively. Differential outputs $f_{0}+$ and $f_{0}-$ are combined with balun for single-end output. Finally, the designed Colpitts VCOs are fabricated with $130 \mathrm{~nm}$ BiCMOS process, which is shown in Figure 4, with a core size of $860 \mu \mathrm{m} \times 690 \mu \mathrm{m}$, excluding the pads.

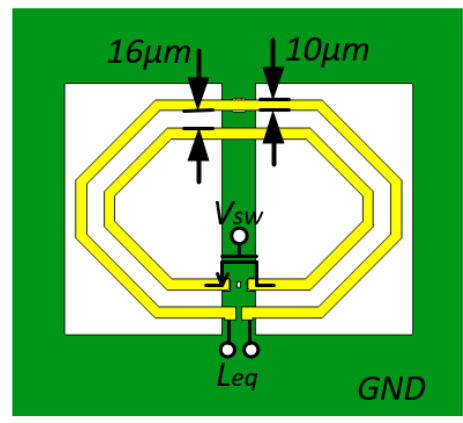

(a)

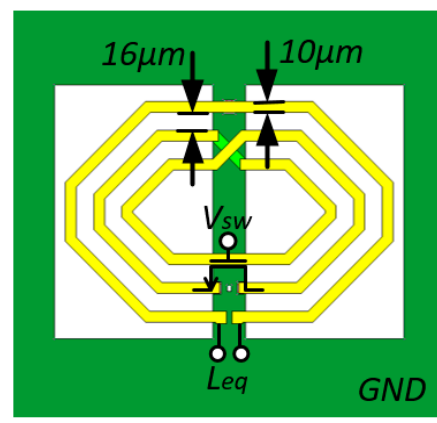

(b)

Figure 3. Cont. 


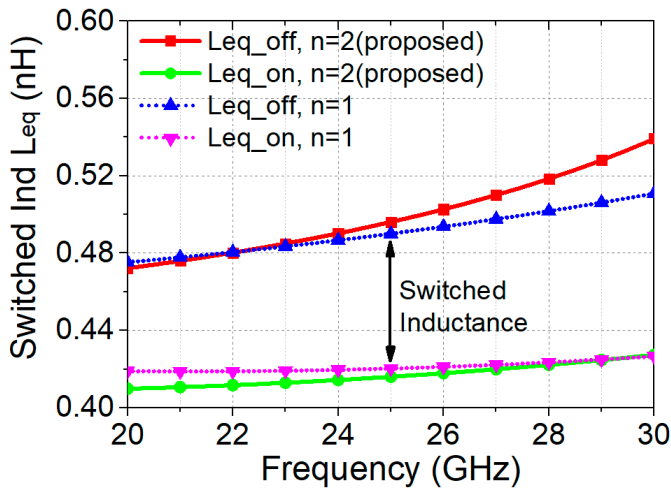

(c)

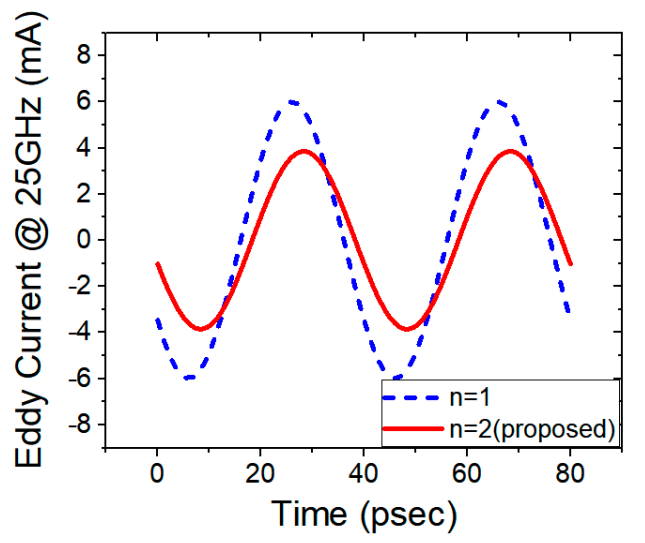

(e)

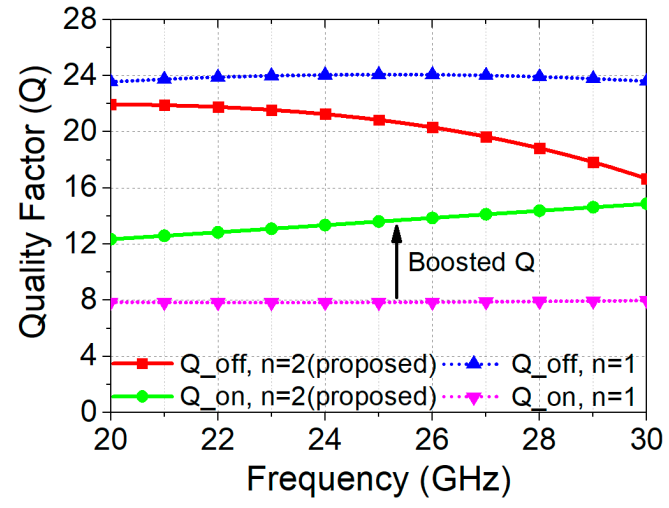

(d)

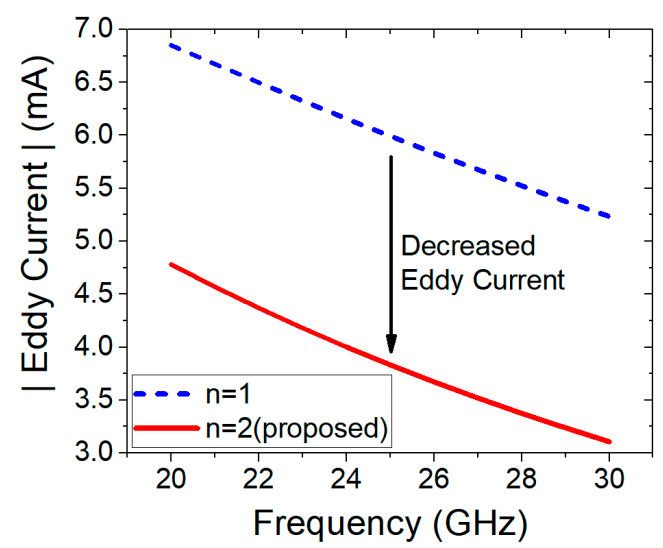

(f)

Figure 3. (a) Normal switched inductor with 1:1 inductor-loaded transformer; (b) the proposed Q-boosted switched inductor; (c) simulated inductance $\mathrm{L}_{\mathrm{eq}}$ at switch ON/OFF state; (d) simulated Q at switch ON/OFF state; (e) simulated transient Eddy current on switch transistor at $25 \mathrm{GHz}$ for $\mathrm{n}=1$ and $\mathrm{n}=2$ (proposed); (f) simulated the magnitude of Eddy currents from 20-30 GHz for $\mathrm{n}=1$ and $\mathrm{n}=2$ (proposed).

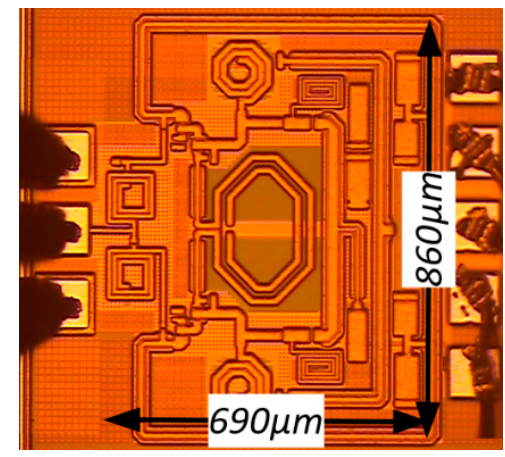

(a)

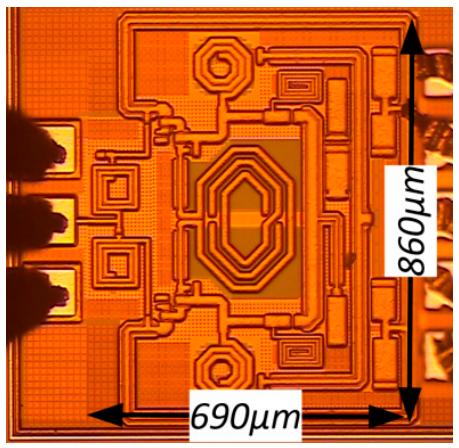

(b)

Figure 4. K-band Colpitts VCO using (a) normal switched inductor with 1:1 inductor-loaded transformer; (b) the proposed Q-boosted switched inductor. 


\section{Results}

The K-band Colpitts VCO chips are wire-bonded to the PCB board for DC biasing and tested with Zprobe GSG probe. The output spectrum and phase noise of the VCOs are measured with R\&S signal source analyzer FSUP50, which also provides biasing voltage $V_{d d}, V_{b} V_{t}, V_{s w}$ to the chip. Figure $5 a$ shows the measurement setup environment, and Figure $5 b$ shows the output spectrum for the Colpitts VCO with the Q-boosted inductor, where the VCO outputs $3.7 \mathrm{dBm}$ (after calibration) at 25.557 $\mathrm{GHz}$, with $\mathrm{V}_{\mathrm{dd}}=2.8 \mathrm{~V}, \mathrm{I}_{\mathrm{dd}}=35 \mathrm{~mA}$, at $\mathrm{V}_{\mathrm{t}}=0.3 \mathrm{~V}$, and $\mathrm{V}_{\mathrm{sw}}=0 \mathrm{~V}$. Figure 6a shows the output frequency range of VCO with Q-boosted switched inductor is from 24.998 to $27.134 \mathrm{GHz}$ for switch OFF-state $\left(\mathrm{V}_{\mathrm{sw}}=0 \mathrm{~V}\right)$, and 26.432 to $28.672 \mathrm{GHz}$ for switch $\mathrm{ON}$-state $\left(\mathrm{V}_{\mathrm{sw}}=1.2 \mathrm{~V}\right)$, which is very close to the frequency tuning range of $\mathrm{VCO}$ using conventional switched inductor.

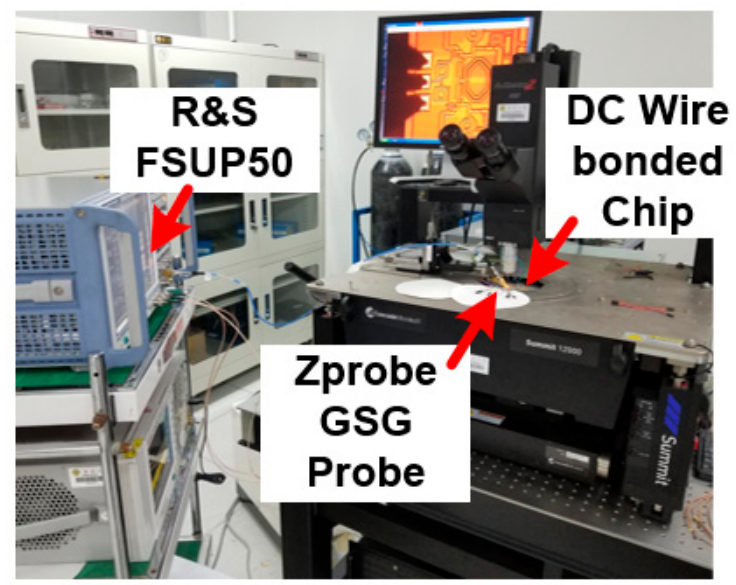

(a)

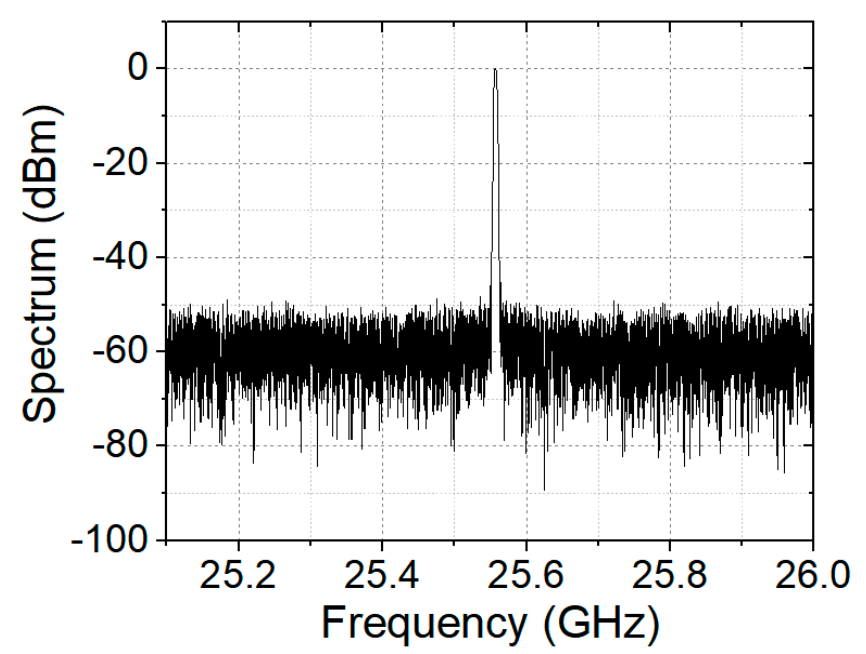

(b)

Figure 5. (a) Measurement setup; (b) output spectrum of Colpitts VCO with Q-boosted inductor at $\mathrm{V}_{\mathrm{t}}=0.3 \mathrm{~V}$, and $\mathrm{V}_{\mathrm{SW}}=0 \mathrm{~V}$. 


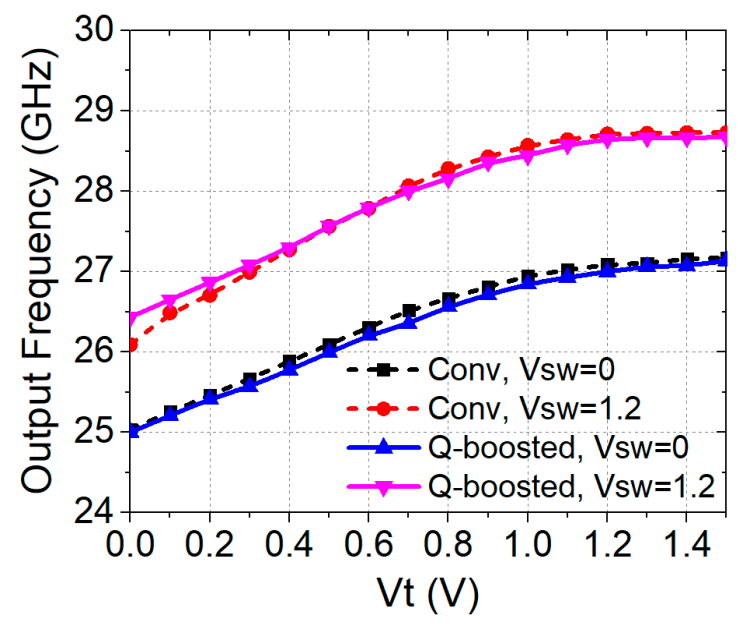

(a)

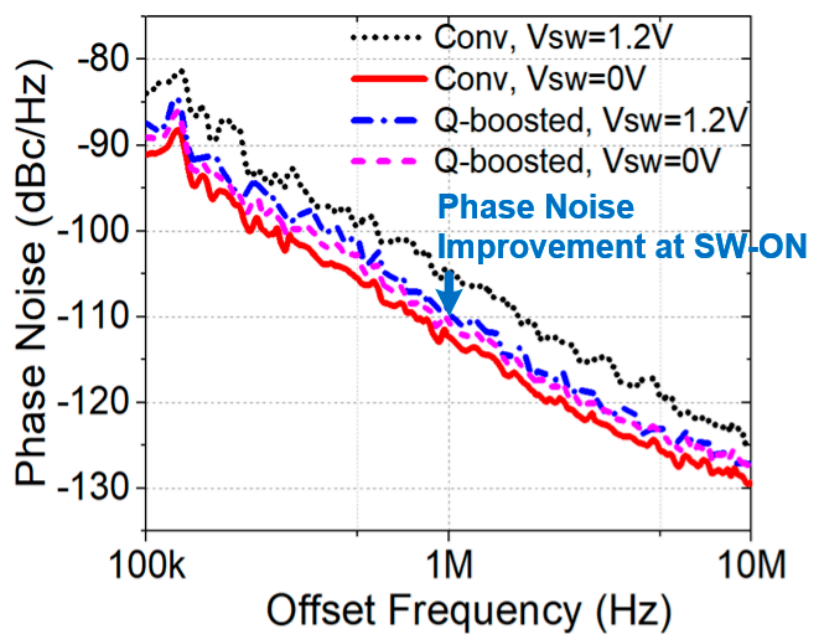

(b)

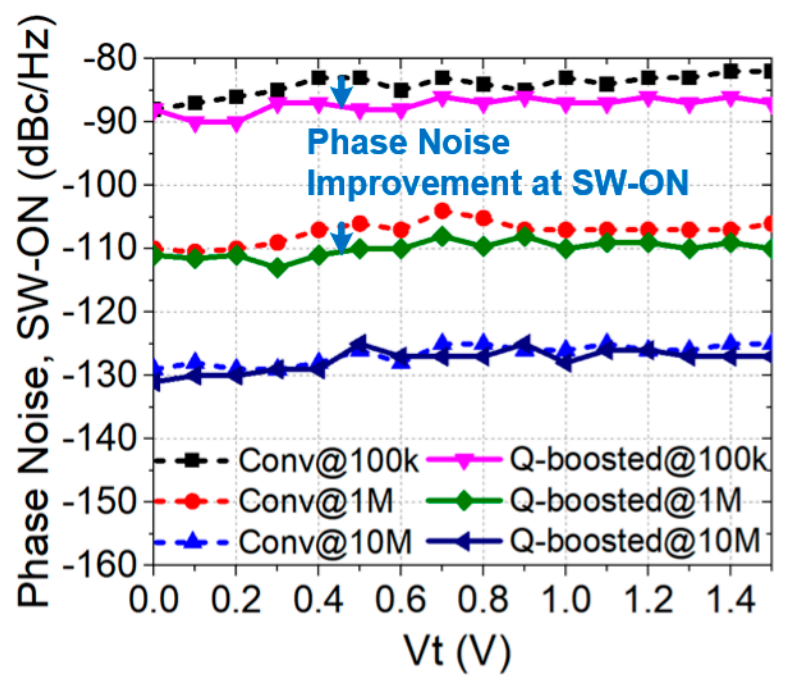

(c)

Figure 6. Measured results for K-band Colpitts VCOs using conventional switched inductor and proposed Q-boosted switched inductor, under switch ON/OFF states: (a) output frequency range; (b) phase noise performance at $\mathrm{V}_{\mathrm{t}}=0.8 \mathrm{~V}$; (c) phase noise vs. $\mathrm{V}_{\mathrm{t}}$ at switch ON-state. 
Figure $6 \mathrm{~b}$ shows the measured VCO phase noise from $100 \mathrm{kHz}$ to $10 \mathrm{MHz}$ offset under the switch ON/OFF states, when $\mathrm{V}_{\mathrm{t}}=0.8 \mathrm{~V}$. VCO using the conventional inductor shows best phase noise at the switch OFF-state $\left(V_{S W}=0 \mathrm{~V}\right)$ (red solid line), with $-91 \mathrm{dBc} / \mathrm{Hz} @ 100 \mathrm{kHz}$, and $-112.1 \mathrm{dBc} / \mathrm{Hz} @ 1 \mathrm{MHz}$. However, the phase noise at switch ON-state $\left(\mathrm{V}_{\mathrm{SW}}=1.2 \mathrm{~V}\right)$ (black dot line) degenerates by $\sim 7 \mathrm{~dB}$ to $-84 \mathrm{dBc} / \mathrm{Hz} @ 100 \mathrm{kHz}$, and $-105.2 \mathrm{dBc} / \mathrm{Hz} @ 1 \mathrm{MHz}$. This is expected because of the decreased inductor $\mathrm{Q}$ at the switch ON-state, as shown in Figure 3d. For the VCO using proposed Q-boosted inductor, the phase noise at switch OFF-state (purple dash line) is $-89.1 \mathrm{dBc} / \mathrm{Hz} @ 100 \mathrm{kHz}$ and $-110.7 \mathrm{dBc} / \mathrm{Hz} @ 1 \mathrm{MHz}$. At switch ON-state (blue dash-dot line), the phase noise gently decreases to $-87.4 \mathrm{dBc} / \mathrm{Hz} @ 100 \mathrm{kHz}$ and $-109.6 \mathrm{dBc} / \mathrm{Hz} @ 1 \mathrm{MHz}$. The proposed Q-boosting technique successfully improves VCO phase noise at the switch ON-state by $3.4-4.4 \mathrm{~dB}$ for $100 \mathrm{kHz}$ and $1 \mathrm{MHz}$ offset. The phase noise improvement at $10 \mathrm{MHz}$ offset is less than $\sim 1.5 \mathrm{~dB}$ at the switch ON-state, because it's close to the phase noise floor, which is mainly dependent on the active device and the output power level of oscillators [10]. This can also be further explained with the following phase noise equation,

$$
L\{\Delta \omega\}=10 \log \left[\frac{2 F k T}{P_{\text {Sig }}}\left\{1+\left(\frac{\omega_{0}}{2 Q \Delta \omega}\right)^{2}\right\}\left(1+\frac{\Delta \omega_{1 / f 3}}{|\Delta \omega|}\right)\right]
$$

where $L\{\Delta \omega\}$ is the phase noise at the frequency offset $\Delta \omega$ from the carrier frequency $\omega_{0}, F$ is the phase noise figure from the active device, $P_{S i g}$ is the output power of the oscillator, $Q$ is the quality factor of the LC tank, $\Delta \omega_{1 / \mathrm{f} 3}$ is the $1 / \mathrm{f}^{3}$ corner frequency. At extremely small frequency offsets, the phase noise is mainly contributed by the flicker noise from the active device, which is dependent on the device itself, and difficult to suppress by tank Q. For frequency offset between $\Delta \omega_{1 / \mathrm{f} 3}$ and $\omega_{0} / 2 \mathrm{Q}$, the phase noise is mainly contributed by the up-converted thermal noise, which can be filtered by the RLC tank, so increased Q can help to suppress the phase noise in this region. At large frequency offset, the phase noise is basically the fixed thermal noise floor, which can be improved with increasing output signal power.

It is noted that the Q-boosting technique will slightly degenerate phase noise at switch OFF-state by $\sim 1 \mathrm{~dB}$, due to larger parasitic capacitance and resistance of the secondary coil. This is acceptable because the overall phase noise is mainly limited by ON-state performance, as shown in Figure $6 \mathrm{~b}$. Phase noise comparisons across full tuning range at switch ON state is shown in Figure 6c. It is clear that the proposed Q-boosting technique has typically improved the VCO phase noise at switch ON-state by $2-5 \mathrm{~dB}$ for $100 \mathrm{kHz}$ and $1 \mathrm{MHz}$ offset. Comparison of reported VCOs using switched inductor is listed in Table 1.

Table 1. Comparison of Reported VCOs with Switched Inductors.

\begin{tabular}{|c|c|c|c|c|c|}
\hline References & Technology & $\begin{array}{l}\text { Frequency } \\
\text { (GHz) }\end{array}$ & $\begin{array}{c}\text { PN@1MHz } \\
\text { (SW ON-State) }\end{array}$ & $\begin{array}{c}\text { FOM }^{1} \\
\text { (SW ON-State) }\end{array}$ & $\begin{array}{l}\text { DC Power } \\
(\mathrm{mW})\end{array}$ \\
\hline [2] & $\begin{array}{l}90 \mathrm{~nm} \\
\text { CMOS }\end{array}$ & $10.2-14.6$ & -103 & -177 & 5.7 \\
\hline [3] & $\begin{array}{c}130 \mathrm{~nm} \\
\text { BiCMOS }\end{array}$ & $28.3-33.5$ & -92 & -165 & 40.2 \\
\hline [4] & $\begin{array}{l}28 \mathrm{~nm} \\
\mathrm{CMOS}\end{array}$ & $\begin{array}{l}71.4-76.1 \\
85.6-90.7\end{array}$ & $-108^{2}$ & -171 & 35.6 \\
\hline $\begin{array}{c}\text { This Work } \\
\text { (Conv. SW Ind) }\end{array}$ & $\begin{array}{l}130 \mathrm{~nm} \\
\mathrm{BiCMOS}\end{array}$ & $25-28.7$ & -105 & -173.5 & $98^{3}$ \\
\hline $\begin{array}{c}\text { This Work } \\
\text { (Q_Boosted Ind) }\end{array}$ & $\begin{array}{l}130 \mathrm{~nm} \\
\mathrm{BiCMOS}\end{array}$ & $25-28.6$ & -110 & -178.5 & $98^{3}$ \\
\hline
\end{tabular}

${ }^{1} \mathrm{FOM}=\mathrm{PN}-20 \log \left(f_{0} / \Delta \mathrm{f}\right)+\mathrm{P}_{\mathrm{DC}}(\mathrm{dBm}) ;{ }^{2}$ Phase noise at $10 \mathrm{MHz}$ offset; ${ }^{3}$ with buffer DC consumption. 


\section{Conclusions}

In this article, the development of K-band low phase noise VCO based on Q-boosted switched inductor is presented. The eddy current will be decreased with the 2-turn secondary coil, and the dissipated power from switch on-resistance will also be decreased, leading to a boosted inductor $Q$ at the switch ON-state. The equivalent inductance, quality factor, and self-resonance frequency at the switch ON/OFF states are analyzed and derived. The prototype has been designed and fabricated with the Q-boosted and conventional switched inductor in $130 \mathrm{~nm}$ BiCMOS process. Measured results show that the phase noise has been typically improved by $2-5 \mathrm{~dB}$ for $100 \mathrm{kHz}$ and $1 \mathrm{MHz}$ offset at switch ON-state, with the Q-boosting technique. The degeneration of phase noise at switch OFF-state is $\sim 1 \mathrm{~dB}$, which is acceptable because the phase noise of VCOs with a switched inductor is mainly limited by ON-state performance. The Q-boosting approach for the K-band switched inductor can be easily scaled down to $90 / 28 \mathrm{~nm}$ process, or even another planar circuit, like LTCC, as long as the process can support multi-turn inductor structures.

Author Contributions: Conceptualization, Z.C.; formal analysis, Z.C. and J.-X.C.; circuit design, Z.C.; validation, D.H. and P.Y.; review and editing, Z.C. and F.Z.

Funding: This research was funded by National Natural Science Foundation of China under Grant 61701114, and the National Science and Technology Major Project under Grant no. 2017ZX03001020.

Conflicts of Interest: The authors declare no conflict of interest.

\section{References}

1. Berny, A.D.; Niknejad, A.M.; Meyer, R.G. A 1.8-GHz LC VCO with 1.3-GHz tuning range and digital amplitude calibration. IEEE J. Solid-State Circuits 2005, 4, 909-917. [CrossRef]

2. Demirkan, M.; Bruss, S.P.; Spencer, R.R. Design of Wide Tuning- Range CMOS VCOs Using Switched Coupled-Inductors. IEEE J. Solid-State Circuits 2008, 43, 1156-1163. [CrossRef]

3. Meng, Y.F.; Frank, B.M.; Gabaly, A.E. A Novel Variable Inductor-Based Differential Colpitts VCO Design with 17\% Frequency Tuning Range for 30 and 60 GHz Applications. In Proceedings of the 2014 IEEE MTT-S International Microwave Symposium (IMS2014), Tampa, FL, USA, 1-6 June 2014; pp. 1-4.

4. Vigilante, M.; Reynaert, P. A Dual-Band E-Band Quadrature VCO with Switched Coupled Transformers in 28nm HPM bulk CMOS. In Proceedings of the 2015 IEEE Radio Frequency Integrated Circuits Symposium (RFIC2015), Phoenix, AZ, USA, 17-19 May 2015; pp. 1-4.

5. Zhang, J.; Sharma, N.; O, K.K. 21.5-to-33.4 GHz voltage controlled oscillator using NMOS switched inductors in CMOS. IEEE Microw. Wirel. Compon. Lett. 2014, 24, 478-480. [CrossRef]

6. You, P.L.; Huang, T.H. A switched inductor topology using a switchable artificial grounded metal guard ring for wide-FTR MMW VCO applications. IEEE Trans. Electron Devices 2013, 60, 759-766. [CrossRef]

7. Agarwal, P.; Sah, S.P.; Molavi, R. Switched Substrate-Shield-Based Low-Loss CMOS Inductors for Wide Tuning Range VCOs. IEEE Trans. Microw. Theory Tech. 2017, 65, 2964-2976. [CrossRef]

8. Almalaq, Y.; Matin, M. Three Topologies of a Non-Isolated High Gain Switched-Inductor Switched-Capacitor Step-Up Cuk Converter for Renewable Energy Applications. Electronics 2018, 7, 94. [CrossRef]

9. Chen, Z.; Fan, K.; Zhai, J. Q-boosted switched inductor based on 1:2 transformer. Microw. Opt. Technol. Lett. 2019, 61, 2635-2639. [CrossRef]

10. Lee, T.H.; Hajimiri, A. Oscillator phase noise: A tutorial. IEEE J. Solid-State Circuits 2000, 35, 326-336. [CrossRef]

(C) 2019 by the authors. Licensee MDPI, Basel, Switzerland. This article is an open access article distributed under the terms and conditions of the Creative Commons Attribution (CC BY) license (http://creativecommons.org/licenses/by/4.0/). 